\section{Ju Hyung Lee ${ }^{1}$, Sung Han $\mathrm{Oh}^{1}$, Pyung Goo Cho', Eun Mi Han², Je Beom Hong ${ }^{3}$}

Departments of ${ }^{1}$ Neurosurgery and ${ }^{2}$ Pathology, Bundang Jesaeng General Hospital, Seongnam, ${ }^{3}$ Department of Neurosurgery, CHA Bundang Medical Center, CHA University, Seongnam, Korea

\section{Corresponding Author:}

Sung Han Oh

Department of Neurosurgery,

Bundang Jesaeng General

Hospital, 20 Seohyeon-ro

180beon-gil, Bundang-gu,

Seongnam 13590, Korea

Tel: $+82-31-779-6500$

Fax: +82-31-779-0895

E-mail: shoh1@dmc.or.kr

Received: May 15, 2017

Revised: August 17, 2017

Accepted: August 18, 2017
Copyright (C) 2017 by The Korean Spinal Neurosurgery Society

This is an open access article distributed under the terms of the Creative Commons Attribution Non-Commercial License (http://creativecommons.org/licenses/bync/4.0/) which permits unrestricted noncommercial use, distribution, and reproduction in any medium, provided the original work is properly cited.

\title{
Solitary Osteochondroma Presenting as a Dumbbell Tumor Compressing the Cervical Spinal Cord
}

We report a case of a solitary osteochondroma as a dumbbell tumor compressing the spinal cord and its surgical strategy. The patient is a 16-year-old female with longstanding posterior neck pain and left arm abduction weakness. She was examined by plain X-ray, three-dimensionalcomputed tomography, magnetic resonance imaging, and vertebral angiography. The analyses indicated a calcified extradural mass compressing the cord in the C3-4 portion extending into the neural and vertebral foramen with eroded vertebral body. The tumor was successfully excised using a modified combined anterior and posterior approach. Histopathologic study of the resected material confirmed the diagnosis. The postoperative assessment was followed by clinical and radiologically therapy for 5 years after surgery. Osteochondroma arises from enchondral bone but it rarely involves the spine, especially not as $\mathbf{s}$ dumbbell type. In this patient, the tumor may have arisen from the neural arch and extended into the extradural and extraforaminal space over a long period. We successfully removed the dumbbell tumor with a combined anterior oblique and posterior approach. However, further observation is essential because of the possibility of recurrence and sarcomatous change.

Key Words: Dumbbell shaped tumor, Osteochondroma, Spinal cord compression

\section{INTRODUCTION}

Most spinal dumbbell tumors are neurogenic tumors, including slow-growing tumors such as ependymomas, vertebral chordomas, meningiomas, and the rare types of nerve sheath tumors, ganglioneuromas and neurofibrosarco$\mathrm{mas}^{3)}$. However, in this study we report a case of solitary osteochondroma presenting itself as a dumbbell tumor compressing the cervical spinal cord and the required surgical strategy. In regard to the surgical strategy, there was some controversy over the removal of the cervical dumbbell tumor ${ }^{6}$. In this young female, we successfully performed a combined anterior oblique and posterior approach with laminoplasty.

\section{CASE REPORT}

This case report was confirmed by the patient and the patient signed the informed consent form, A 16-year-old female visited our clinic complaining about progressive neck pain and left arm abduction weakness (grade III) over the past 2 years. She was examined by plain X-ray, three-dimensional (3D)-computed tomography, magnetic resonance imaging, and vertebral artery angiogram. The analyses indicated a calcified extradural mass with a size of about $3 \mathrm{~cm} \times 2.4 \mathrm{~cm}$, ill-defined, compressing the cord in the $\mathrm{C}^{-4} 4$ portion, and extending into the neural foramen with eroded vertebral body. A vertebral angiography showed a left side hypoplastic vertebral artery (Fig. 1).

There was no evidence of family history and long bone deformities revealing the multiple hereditary exostosis.

The tumor was successfully excised using a modified combined anterior oblique and posterior approach. In this approach, the extraforaminal portion of the tumor was first removed through the anterior oblique approach. For this, the patient's body including the neck was tilted to the right side for a proper surgical view to avoid vertebral artery injury using an intraoperative doppler. In the second part, the intracanal portion of the tumor was removed via a posterior approach with $\mathrm{C} 3 / \mathrm{C} 4$ laminoplasty under intraoperative neuro-monitoring (Fig. 2). The tumor showed a dark-red colored leather-like consistency with some calcification.

A histopathologic study of the resected material showed a cartilaginous cap and an underlying bone with enchondral ossification. The cartilaginous cap demonstrated chondrocytes without cytologic atypia comparable with osteochondroma (Fig. 3).

Postoperative, the symptoms of the female were improved. Clinical and radiological assessments were performed in the 5 years after the operation. Clinically, she was symptom-free 


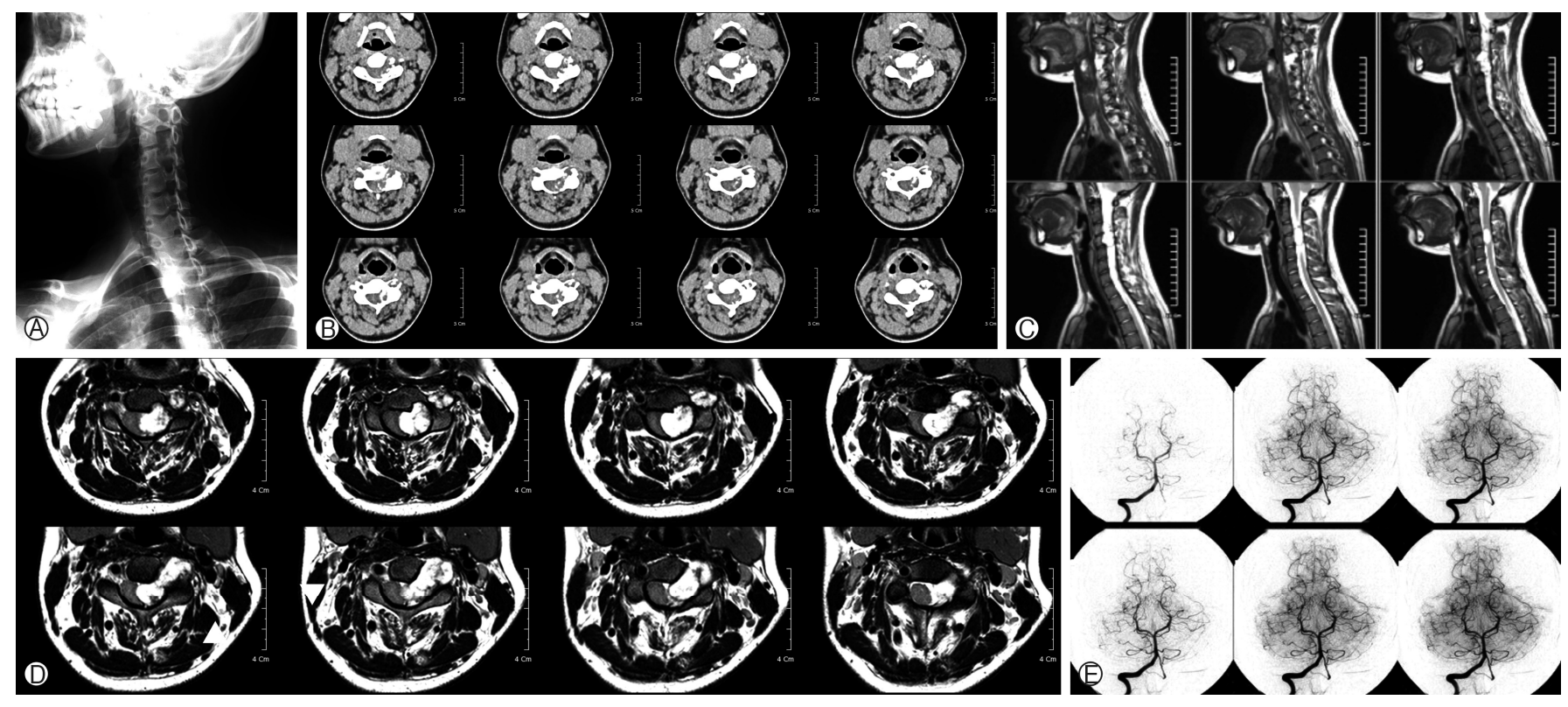

Fig. 1. Preoperative imaging studies. (A) A plain X-ray of cervical oblique view showing C3-4 eroded neural foraminal widening. (B) Computed tomography revealing ill-defined, calcified mass at the left side of the spinal canal with extension to extra-foraminal space and vertebral foramen at the C3-4 level (axial view). (C) Magnetic resonance images demonstrating a mass of the size of about $3 \mathrm{~cm} \times 2.4 \mathrm{~cm}$ (T2-sagittal view). (D) Magnetic resonance images showing a dumbbell-shaped mass through the vertebral foramen and compressing the cervical cord (T2-axial view). (E) Vertebral angiographic showing hypoplastic left side vertebral artery.

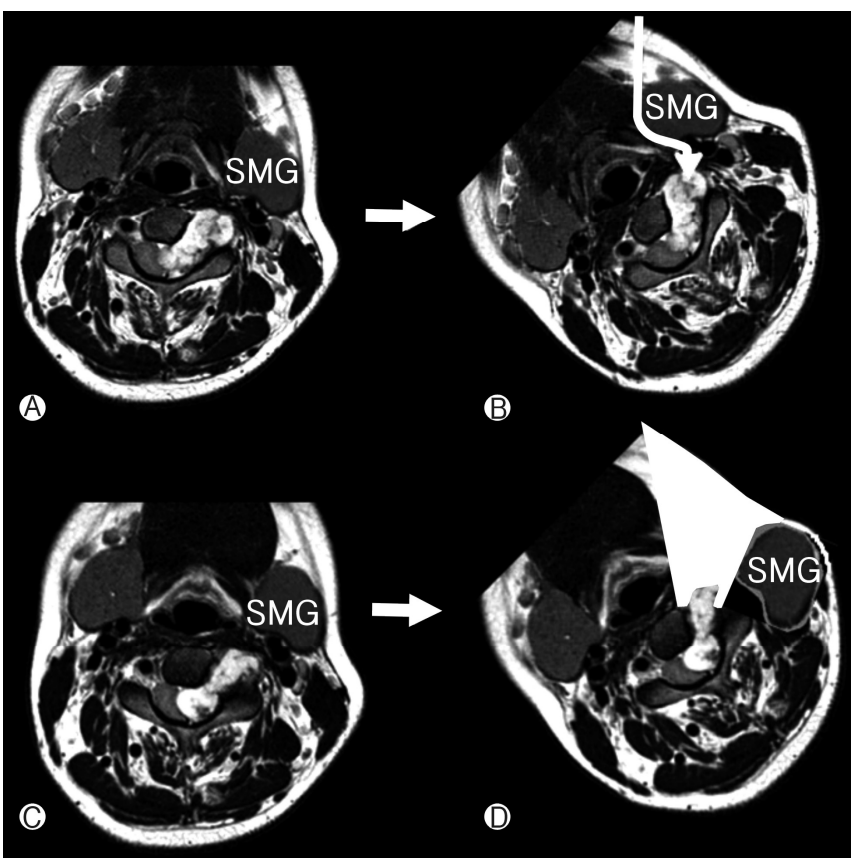

Fig. 2. Surgical corridor of the anterior oblique approach. (A, C) The neck of the patient was rotated to the right side $(\mathrm{B}, \mathrm{D})$ to provide an effective surgical view. (B) Surgical corridor (yellow colored curved arrow). (D) Surgical working space (yellow colored area). SMG, Submandibular gland.

and there was neither a spinal instability nor kyphosis or tumor
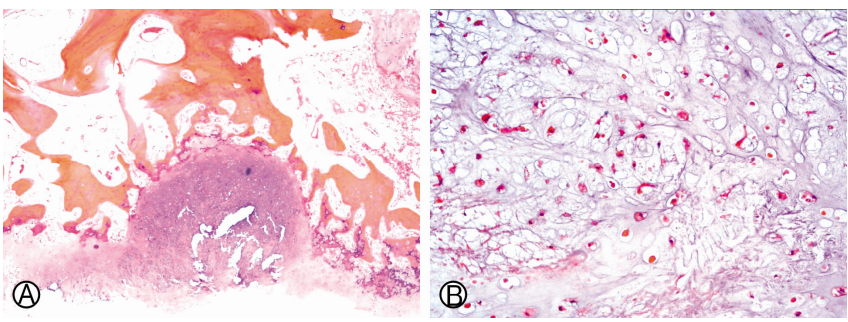

Fig. 3. Histopathologic confirmation of the osteochondroma. (A) Histologic finding shows cartilaginous cap and underlying bone with enchondral ossification $(\mathrm{H} \& \mathrm{E}, \times 40)$. (B) Cartilaginous cap showing chondrocytes without cytologic atypia $(\mathrm{H} \& \mathrm{E}, \times 200)$.

recurrence in the imaging studies (Fig. 4).

\section{DISCUSSION}

Osteochondromas are common benign long bone tumors in young adults. However, they rarely involve the spinal column. Moreover, its presentation as compressive myelopathy is rare. Most of the literature of these tumors is in form of case reports.

The term "dumbbell tumor" describes spinal tumors that acquire an hourglass shape in the course of their growth as they encounter an anatomic barrier such as the dura mater, a nerve root foramen, or bony elements. Various tumoral, vascular, and developmental causes may lead to dumbbell lesions ${ }^{5,15,17,18)}$.

However, to our knowledge, a solitary osteochondroma presenting itself as a dumbbell tumor in the cervical spine is not 


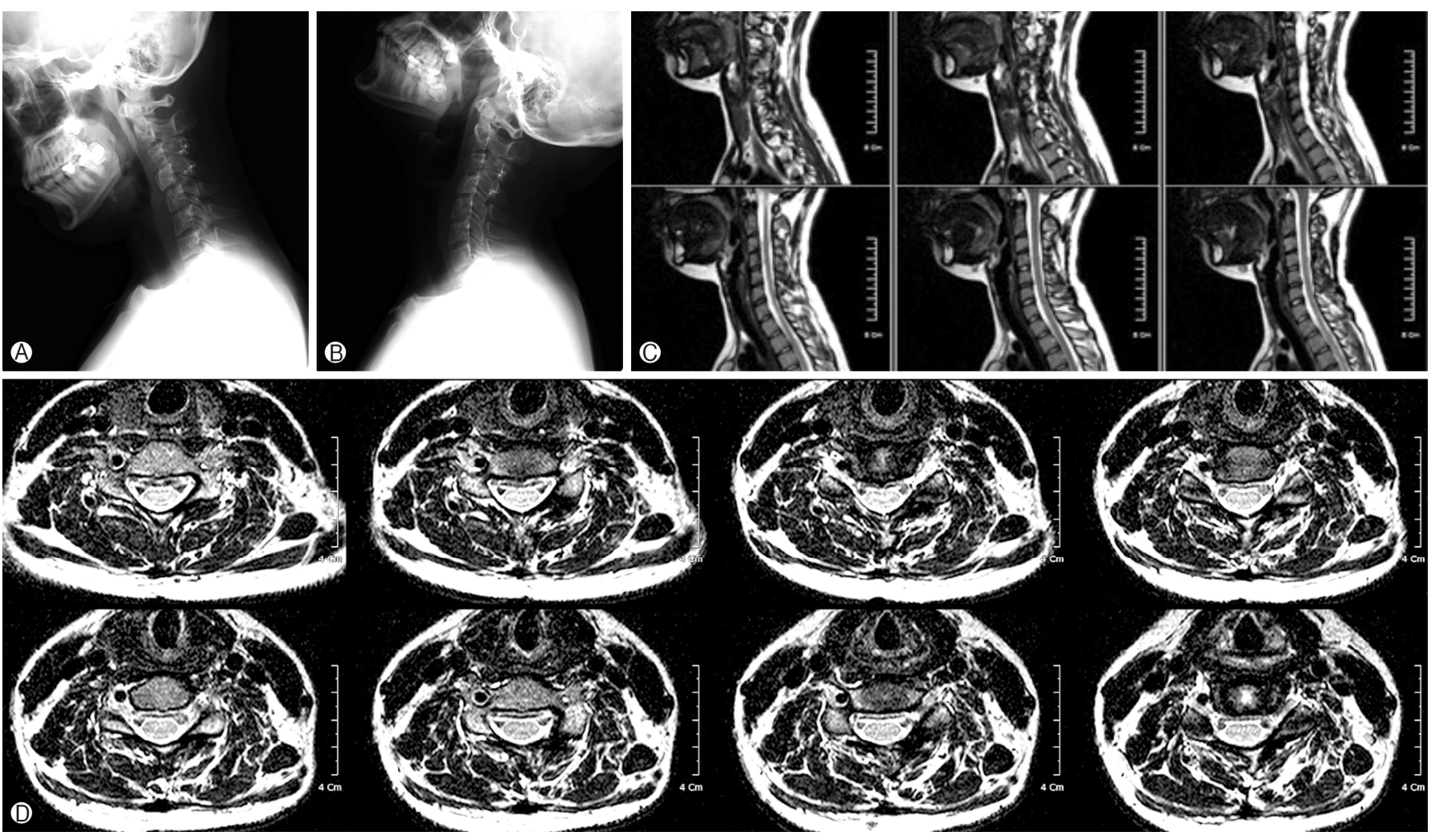

Fig. 4. Postoperative images after 5 years of operation. (A) A plain dynamic X-ray of the cervical spine after laminoplasty showing no instability (flexion view). (B) A plain dynamic X-ray of the cervical spine after laminoplasty showing no instability (extension view). (C) Magnetic resonance images demonstrating no residual mass, 5 years after operation (T2-sagittal view). (D) Magnetic resonance images revealing no residual mass, 5 years after operation (T2-axial view).

reported yet. In this patient, a slow growing osteochondroma may have passed through the corresponding neural foramen, widened, and led to the so-called "dumbbell" lesion.

The finding in this patient should be considered as an osteochondroma that can be included as a rare condition in the differential diagnosis of spinal dumbbell tumors ${ }^{16)}$.

Osteochondromas are thought to arise via a process of progressive enchondral ossification of aberrant cartilage of a growth plate as a result of a congenital defect or trauma. In contrast, hereditary multiple exostoses may occur sporadically as a part of an autosomal dominant gene with variable expression ${ }^{12)}$. In cases of the osteochondroma of the spine, the most common location is cervical ${ }^{4,10)}$ and arises from the tip of a spinous or transverse process and rarely causes neurological symptoms ${ }^{14)}$. Radiation-induced osteochomdroma may possibly be caused by a failure of the reserve cell layer in the epiphyseal growth zone.

According to Albrecht et al. ${ }^{2}, 30 \%$ of spinal solitary osteochondroma lead to spinal cord compression. However, a neurologic disease is thought to be the result of progressive encroachment of the slowly expanding osteochondroma on neural structures. A similar case as ours was reported in the literature of a 65-year-old patient with a manifested dumbbell mass passing through the thoracic neural foramen leading to cord compression. The patient was treated using hemilaminectomy with subtotal tumor excision. A clinical follow-up 2 years later revealed normal findings in that case ${ }^{16}$. In our case, postoperative follow-up for the next 5 years revealed neither radiologically tumor recur nor spinal instability.

The surgical removal is mandatory if compressing myelopathy exists. Generally, a surgical outcome is good. However, a recurrence after surgery is possible in case of incomplete removal of the cartilaginous cap ${ }^{19}$. In case of a recurrence, one should anticipate the possibility of malignant transformation of the osteochondroma or of a low-grade chondrosarcoma initially poorly classified. The risk of malignant transformation of multiple osteocartilaginous exostoses is well known. However, a malignant tumor developing from a solitary osteochondroma is rarely observed $^{2)}$.

Current results in surgical approaches for spinal cord compression due to spinal solitary osteochondroma are generally good. For example, only $15 \%$ of patients failed to improve after surgery or even worsened by a decompressive procedure ${ }^{8}$. But there has been some controversy in regard to surgical methods of the cervical dumbbell type tumor.

Several authors recommended an anterolateral approach. The advantage of this approach is good surgical views, but it is unfamiliar to most neurosurgeons ${ }^{7,9)}$. On the other hand, Lot and George $^{13)}$ insisted on complete excision using a lateral approach 
and vertebral artery control. However, a lateral approach still carries the risk of injuring not only the vertebral artery but also the phrenic, vagus, accessory, or hypoglossal nerves.

Eun $^{6}$ reported a modified posterior midline exposure with laminectomy and complete facetectomy in most cases of cervical dumbbell Schwannomas. Advantages of a combined posterior and anterior approach have been described by several authors, ${ }^{1,11)}$.

Asazuma et al. ${ }^{3)}$ recommended that imaging-based 3D characterization of the shape and location of cervical dumbbell tumors are essential for planning optimal surgery.

We attained preoperative 3D images and performed a modified combined anterior oblique approach for an eccentrical-located extraforaminal tumor excision on the left side. The body and neck of the patient were tilted to the contralateral side of the tumor. That is nearly the same position as the oblique view of the plain X-ray. It is straight vertical to the longitudinal axis of the extraforaminal part of the tumor in three dimensions. This position provided an effective surgical corridor and the shortest distance to the tumor (Fig. 2). Next, a posterior approach for the intracanal part of tumor removal was performed with laminoplasty without solid fusion. Intraoperative neuro-monitoring was performed during the operation. Although we removed the mass around the vertebral artery using the doppler, there may remain a little tumor around the vertebral artery. However, we observed neither a tumor growth nor sarcomatous change in the next 5 years after surgery. Thus, we assume that the tumor around the vertebral artery may regress while the patient is growing up. This combined approach resulted in a nearly total tumor resection without vertebral artery injury, nor instability or kyphotic change (Fig. 4).

There was a radiologic similar case of cervical neural foramen widening chondrosarcoma in the literature ${ }^{20)}$. Contrary to that article, our histopathologic diagnosis was more benign nature osteochodroma that has not recurred, nor sarcomatous change during 5 years after surgery. We proposed surgical staged strategy for safe and complete removal of the tumor.

\section{CONCLUSION}

Osteochondroma arises from enchondral bone, but it rarely involves the spine. In this patient, the tumor may have arisen from the neural arch and extended into the extradural and extraforaminal space over a long period. Appearance of dumbbellshaped tumor in the spine is usually a neurogenic tumor. However, we report a solitary osteochondroma presenting itself as a cervical dumbbell tumor. In this case, we propose a modified combined anterior oblique and posterior approach with laminoplasty as an option for tumor extension. However, further observation is essential because of the possibility of recurrence and sarcomatous change.

\section{CONFLICT OF INTEREST}

No potential conflict of interest relevant to this article was reported.

\section{REFERENCES}

1. Adson AW: Surgical consideration of intraspinal tumors. J Int Coll Surg 14:1-11, 1950

2. Albrecht S, Crutchfield JS, SeGall GK: On spinal osteochondromas. J Neurosurg 77:247-252, 1992

3. Asazuma T, Toyama Y, Maruiwa H, Fujimura Y, Hirabayashi K: Surgical strategy for cervical dumbbell tumors based on a threedimensional classification. Spine (Phila Pa 1976) 29:E10-14, 2004

4. Calhoun JM, Chadduck WM, Smith JL: Single cervical exostosis. Report of a case and review of the literature. Surg Neurol 37:2629, 1992

5. Cheng TJ, Wu TT, Hsu JD: A dumbbell spinal lipoma presenting as a neck mass: CT and MR demonstration. Pediatr Radiol 25:570571, 1995

6. Eun JP: Surgical experiences of dumbbell tumors of the cervical spine using a modified posterior midline exposure with laminectomy and complete unilateral facetectomy. Korean J Spine 2:7-13, 2005

7. George B, Lot G: Neurinomas of the first two cervical nerve roots: a series of 42 cases. J Neurosurg 82:917-923, 1995

8. Gille O, Pointillart V, Vital JM: Course of spinal solitary osteochondromas. Spine (Phila Pa 1976) 30:E13-19, 2005

9. Hakuba A, Komiyama M, Tsujimoto T, Ahn MS, Nishimura S, Ohta T, et al: Transuncodiscal approach to dumbbell tumors of the cervical spinal canal. J Neurosurg 61:1100-1106, 1984

10. Khosla A, Martin DS, Awwad EE: The solitary intraspinal vertebral osteochondroma. An unusual cause of compressive myelopathy: features and literature review. Spine (Phila Pa 1976) 24:77-81, 1999

11. Kim JH, Han S, Kim JH, Kwon TH, Chung HS, Park YK: Surgical consideration of the intraspinal component in extradural dumbbell tumors. Surg Neurol 70:98-103, 2008

12. Ko WW, Kong DS, Eoh W, Kim ES: Cervical osteochondroma in a patient with hereditary multiple exostosis: a case report. Korean J Spine 2:373-376, 2005

13. Lot G, George B: Cervical neuromas with extradural components: surgical management in a series of 57 patients. Neurosurgery 41: 813-820, 1997

14. Moriwaka F, Hozen H, Nakane K, Sasaki H, Tashiro K, Abe H: Myelopathy due to osteochondroma: MR and CT studies. J Comput Assist Tomogr 14:128-130, 1990

15. Schima W, Stiglbauer R, Trattnig S, Heimberger K, Kramer J, Imhof $\mathrm{H}$ : Case report: cervical intervertebral foramen widening caused by vertebral artery tortuosity--diagnosis with MR and colour-coded Doppler sonography. Br J Radiol 66:165-167, 1993

16. Sener RN: Osteochondroma of the thoracic spine: a dumbbell mass associated with spinal cord compression. Comput Med Imaging Graph 22:361-363, 1998

17. Sener RN, Alper H, Yunten N, Yalin T: Agenesis of a sacral pedicle and superior facet: CT and MR demonstration. Eur Radiol 4:587588, 1994

18. Sener RN, Ripeckyj GT, Jinkins JR: Agenesis of a lumbar pedicle: MR demonstration. Neuroradiology 33:464, 1991

19. Shapiro SA, Javid T, Putty T: Osteochondroma with cervical cord compression in hereditary multiple exostoses. Spine (Phila Pa 1976) 15:600-602, 1990

20. Yünten N, Calli C, Zileli M, Ustün EE, Sener RN: Chondrosarcoma causing cervical neural foramen widening. Eur Radiol 7:1028-1030, 1997 